\title{
PENGARUH MODEL CONTEXTUAL TEACHING AND LEARNING (CTL) TERHADAP HASIL BELAJAR SISTEM BAHAN BAKAR BENSIN
}

\author{
I Made Adwesta Wirya ${ }^{1}$, Wiyogo $^{2}$, Jhonni Rentas Duling ${ }^{3}$ \\ ${ }^{1,2,3}$ Fakultas Keguruan dan Ilmu Pendidikan, Universitas Palangka Raya \\ E-mail: madeadwesta78@gmail.com
}

\begin{abstract}
The purpose of this study was to determine the Effect of Contextual Teaching and Learning (CTL) Model on Student Learning Outcomes on Conventional Gasoline Fuel Systems Lesson in TBSM XI Class of SMKN 1 Palangka Raya, Academic Year 2017/2018. The method used in this study is pre-experimental design, by using one-group pretest-posttest design. In this design there is a pretest before treatment. Thus the results of the treatment can be known more accurately, because it can compare with the situation before being treated. The results of this study indicate that the calculation using the t-test with a significance level of $\alpha=0.05$ obtained a tcount value of 16.19 while the $t$ _table value was 1.992 . Because $t \_$count $>t$ table, this means that $\mathrm{H}_{0}$ is rejected and $\mathrm{H}_{1}$ is accepted, so it can be concluded that there are influences of student learning outcomes taught using the CTL model on conventional gasoline fuel system lesson. The type of learning model is quite effective in the process of teaching in schools especially automotive lesson.
\end{abstract}

Keywords: contextual teaching and learning, learning outcomes, automotive

\section{PENDAHULUAN}

Undang-undang Sistem Pendidikan Nasional (UUSPN) No. 20 tahun 2003 pasal 15 menyatakan bahwa pendidikan kejuruan adalah pendidikan menengah yang mempersiapkan peserta didik terutama untuk bekerja dalam bidang tertentu. Pendidikan kejuruan adalah pendidikan yang menghubungkan, menjodohkan, melatih manusia agar memiliki kebiasaan bekerja untuk dapat memasuki dan berkembang pada dunia kerja (industri), sehingga dapat dipergunakan untuk memperbaiki kehidupannya. Adapun tujuan khusus Sekolah Menengah Kejuruan (SMK) adalah: (1) menyiapkan peserta didik agar dapat bekerja, baik secara mandiri atau mengisi lapangan pekerjaan yang ada di dunia usaha dan industri sebagai tenaga kerja tingkat menengah, sesuai dengan bidang dan program keahlian yang diminati, (2) membekali peserta didik agar mampu memilih karir, ulet dan gigih dalam berkompetensi dan mampu mengembangkan sikap profesional dalam bidang keahlian yang diminati, dan (3) membekali peserta didik dengan Ilmu Pengetahuan dan Teknologi (IPTEK) agar mampu mengembangkan diri sendiri melalui jenjang pendidikan yang lebih tinggi.

SMK baik berstatus negeri maupun swasta dituntut sebagai wadah pembentukan siswa yang memiliki kemampuan soft skill, dan hard skill yang baik, serta diharapkan lebih meningkatkan proses pembelajaran khususnya dalam bidang praktik. Kompetensi yang telah siswa peroleh pada saat pembelajaran teori dapat dipraktikan semaksimal mungkin di bengkel (workshop) yang dimiliki, akan tetapi dalam proses pelaksanaan pembelajaran sering kali terjadi ketidaksesuaian antara teori yang diperoleh dengan proses praktik yang dilakukan. Bahkan hasil yang telah dipelajari di sekolah baik teori maupun praktik berbeda dengan kondisi yang ada di dunia kerja.

Untuk mencapai tujuan pendidikan mencerdaskan kehidupan bangsa dibutuhkan proses pendidikan yang baik di setiap satuan pendidikan. SMK adalah satuan pendidikan yang berbasis kejuruan untuk mencetak siswa-siswa yang mempunyai kemampuan dan keterampilan dan siap masuk dunia kerja serta menjadi tenaga kerja yang siap pakai. Dari hasil survei di SMK Negeri 1 Palangka Raya, terdapat program keahlian yang mempelajari tentang sepeda motor yaitu Teknik Bisnis Sepeda Motor (TBSM).

Berdasarkan hasil observasi dengan beberapa guru, pada mata pelajaran Pemeliharaan Mesin Sepeda Motor terdapat meteri pelajaran "Sistem Bahan Bakar Bensin Konvensional". Hasil belajar beberapa siswa pada materi ini masih di bawah Kriteria Ketuntasan Minimum (KKM) 70. Hal ini dikarenakan minimnya alat penunjang belajar seperti LCD Proyektor sehingga harus bergantian dalam penggunannya, pembelajaran monoton yang terfokus kepada guru saja, siswa juga tidak dapat 
menerapkan hasil dari pembelajaran, kurangnya pemahaman siswa tentang hubungan dan manfaat dari materi tersebut sehingga siswa manjadi tidak tertarik mengikuti pelajaran dan menganggap materi ini tidak penting karena itu proses pembelajaran tidak berjalan dengan maksimal.

Dari kenyataan tersebut, maka perlu dicarikan solusi untuk meningkatkan semangat siswa dalam mengikuti pelajaran pada materi "Sistem bahan bakar bensin konvensional". Salah satu solusi pemecahannya adalah dengan menggunakan model Contextual Teaching and Learning (CTL), yang penerapannya cukup mudah. Model CTL digunakan untuk menarik siswa agar semangat mengikuti pelajaran, dengan mengetahui makna dari apa yang mereka pelajari maka siswa akan cenderung menjadi ingin tahu lebih banyak dan menjadi tertarik mengikuti pelajaran tersebut.

CTL merupakan suatu proses pembelajaran holistik yang bertujuan untuk membelajarkan peserta didik dalam memahami bahan ajar secara bermakna (meaningfull) yang dikaitkan dengan konteks kehidupan nyata baik berkaitan dengan lingkungan pribadi, agama, sosial, ekonomi, kultur, dan sebagainya, sehingga peserta didik memperoleh ilmu pengetahuan dan keterampilan yang dapat diaplikasian dan ditransfer dari satu konteks permasalahan yang satu ke permasalahan lainnya (Suhana, 2014:67). Johnson dalam Rusman (2016:187) menyatakan bahwa pembelajaran kontekstual adalah sebuah sistem yang merangsang otak untuk menyusun pola-pola yang mewujudkan makna. Pembelajaran kontekstual adalah suatu sistem pembelajaran yang cocok dengan otak yang menghasilkan makna dengan menghubungkan muatan akademis dengan konteks dari kehidupan sehari-hari siswa.

Model CTL adalah pembelajaran yang mampu memberikan pengalaman kepada siswa, bukan pembelajaran yang hanya sekedar menyuruh siswa untuk menghafal materi. Jika siswa hanya dijejali materi dan disuruh menghafal saja, tanpa adanya peran aktif dari siswa, maka proses belajarnya tidak akan maksimal yang pada akhirnya akan berdampak buruk terhadap hasil belajarnya. Perlu diketahui bersama, pengalaman dalam proses pembelajaran adalah hal yang sangat penting dan urgen demi keberhasilan siswa dalam menguasai materi. Dengan model ini siswa menjadi mengetahui manfaat dan fungsi materi yang di pelajarinya, sehingga siswa menjadi tertarik untuk mengikuti pelajaran tersebut. Hal itu bisa terjadi karena CTL sesuai dengan cara kerja otak dan prinsip-prinsip yang menyokong sistem kehidupan.

Berdasarkan uraian di atas, maka peneliti tertarik untuk melakukan penelitian tentang "Pengaruh Model Pembelajaran CTL terhadap Hasil Belajar Siswa pada Materi Sistem Bahan Bakar Bensin Konvensional di Kelas XI TBSM SMK Negeri 1 Palangka Raya Tahun Ajaran 2017/2018”.

\section{METODE}

Jenis penelitian ini adalah penelitian eksperimen. Desain yang digunakan adalah pre-experimental design jenis one-group pretest-posttest design. Instrumen yang digunakan dalam penelitian ini berupa RPP sebagai bahan perlakuan, tes hasil belajar, dan angket sikap. Sebelum digunakan untuk pengumpulan data, dilakukan uji kelayakan instrumen penelitian, yang hasilnya diringkas pada Tabel 1. Kemudian untuk menganalisis pengaruh model CTL terhadap hasil belajar siswa digunakan statistik uji-t.

Tabel 1. Ringkasan Hasil Pengujian Instrumen

\begin{tabular}{lll}
\hline Jenis Pengujian & Jumlah Soal & Ketarangan \\
\hline Validitas Instrumen & \multirow{2}{*}{50} & 30 soal valid \\
& & 20 soal tidak valid \\
Uji Tingkat Kesukaran & 50 & 3 soal mudah, \\
& & 26 soal cukup, \\
& 21 soal sulit \\
& 1 soal memiliki daya beda kurang \\
Uji Daya Pembeda & 50 & 1 soal memiliki daya beda cukup \\
& & 5 soal memiliki daya beda baik \\
Reliabilitas Soal & 50 & 43 soal memliki daya beda sangat baik \\
& & Reliabilitas tinggi dengan skor 0,73 \\
\hline
\end{tabular}




\section{HASIL DAN DISKUSI}

Uji hipotesis dilakukan dengan statistik parametris, sehingga beberapa asumsi harus terpenuhi. Asumsi yang utama adalah data yang akan dianalisis harus terdistribusi normal. Selanjutnya data pretest dan posttest yang akan diuji harus homogen dari populasi yang sama. Setelah data terbukti terdistribusi normal dan memiliki varian yang homogen, maka dapat dilakukan uji perbedaan rata-rata terhadap data hasil pretest dan posttest menggunakan uji-t.

\section{Uji Normalitas}

Salah satu syarat dalam statistik parametris adalah asumsi bahwa setiap data yang akan dianalisis berdistribusi normal. Dalam penelitian ini digunakan pengujian dengan metode chi-kuadrat $\left(X^{2}\right)$. Uji normalitas ini dilakukan untuk mengetahui apakah data berdistribusi normal atau tidak. Setelah dilakukan pengujian, maka diperoleh data seperti pada Tabel 2.

Tabel 2. Hasil Uji Normalitas Data

\begin{tabular}{lll}
\hline Ukuran Statistika & Pretest & Posttest \\
\hline Rata-rata & 60,16 & 80,32 \\
Standar Deviasi & 6,04 & 4,74 \\
Varian & 36,51 & 22,44 \\
$\mathrm{X}^{2}$ hitung & 5,76 & 4,37 \\
$\mathrm{X}_{\text {tabel }}$ & 11,07 & 11,07 \\
Kesimpulan & Normal & Normal \\
\hline
\end{tabular}

Berdasarkan pengujian normalitas data pretest siswa diperoleh nilai $X_{\text {hitung }}^{2}$ lebih kecil dari nilai $X_{\text {tabel }}^{2}$ yaitu 5,76 < 11,07. Maka dapat disimpulkan bahwa data pretest siswa berdistribusi normal.

Selanjutnya pada pengujian normalitas data posttest siswa diperoleh nilai $X^{2}{ }_{\text {hitung }}$ lebih kecil dari nilai $X_{\text {tabel }}^{2}$ yaitu $4,37<11,07$. Maka dapat disimpulkan bahwa data posttest siswa berdistribusi normal.

\section{Uji Homogenitas}

Uji homogenitas (kesamaan varian) digunakan untuk mengetahui varian populasi, apakah populasi yang datanya akan dianalisis mempunyai yang sama atau berbeda. Data pengujian homogenitas varian dapat dilihat pada Tabel 3.

Tabel 3. Hasil Uji Homogenitas Varian

\begin{tabular}{lll}
\hline Ukuran Statistika & Pretest & Posttest \\
\hline Varian & 36,51 & 22,44 \\
$\mathrm{~F}_{\text {hitung }}$ & 1,62 & \\
$\mathrm{~F}_{\text {tabel }}$ & 1,72 & \\
Kesimpulan & Homogen & \\
\hline
\end{tabular}

Berdasarkan perhitungan $F_{\text {hitung }}$ dan nilai $F_{\text {tabel }}$ di atas, diperoleh $F_{\text {hitung }}=1,62<F_{\text {tabel }}=1,72$, maka kesimpulannya adalah data pretest dan posttest homogen.

\section{Uji Hipotesis}

Setelah dilakukan uji prasyarat data diketahui hasilnya data berdistribusi normal, maka datadata tersebut telah memenuhi syarat untuk uji statistik parametris. Dalam penelitian ini uji keseimbangan rata-rata (uji dua pihak) menggunakan uji-t dua sampel berkorelasi. Tabel 4 berikut menyajikan besaran yang akan digunakan dalam uji-t.

Tabel 4. Besaran Untuk Menguji Hipotesis

\begin{tabular}{lll}
\hline Kelompok & Posttest & Pretest \\
\hline Rata-rata $(X)$ & 80,32 & 60,16 \\
Standar Deviasi (SD) & 4,74 & 6,04 \\
Varian $\left(\mathrm{S}^{2}\right)$ & 22,44 & 36,51 \\
$\mathrm{~T}_{\text {hitung }}$ & 16,19 & \\
$\mathrm{~T}_{\text {tabel }}$ & 1,992 & \\
\hline
\end{tabular}


Berdasarkan analisis data penelitian, diperoleh hasil bahwa terdapat perbedaan rata-rata hasil pretest dengan posttest dengan selisih yang cukup besar. Dimana kemampuan awal siswa dapat dilihat dari nilai rata-rata pretest yaitu 60,16. Setelah dilakukan pembelajaran dengan menggunakan model pembelajaran CTL rata-rata hasil belajar siswa adalah 80,32. Berdasarkan uji $\mathrm{N}$-gain didapatkan skor gain rata-rata siswa adalah 0,49 atau peningkatan kompetensi individu siswa rata-rata dalam kategori sedang. Dari hasil uji normalitas dan uji homogenitas diperoleh hasil bahwa data pretest dan posttest berdistribusi normal dan tidak homogen, sehingga pada uji hipotesis digunakan uji-t. Berdasarkan uji statistik parametris yang dilakukan menghasilkan $t_{\text {hitung }}>t_{\text {tabel }}(16,19>1,99)$. Dengan demikian dapat disimpulkan bahwa "Terdapat pengaruh pada hasil belajar siswa yang signifikan antara sebelum penggunaan model CTL, dengan sesudah penggunaan medel pembelajaran CTL di kelas XI TBSM SMK Negeri 1 Palangka Raya tahun Ajaran 2017/2018". Hal ini menunjukkan bahwa hasil belajar siswa setelah menggunakan model pembelajaran CTL lebih baik dibandingkan hasil belajar siswa sebelum menggunakan model pembelajaran CTL.

\section{SIMPULAN}

Berdasarkan hasil penelitian, diperoleh rerata nilai tes awal (pretest) sebesar 60,16 rerata nilai tes akhir (posttest) sebesar 80,32. Hasil uji normalitas dan uji homogenitas diperoleh kesimpulan bahwa data pretest-posttest berdistribusi normal dan homogen. Selanjutnya dilakukan uji hipotesis menggunakan uji-t dua sampel berkorelasi, diperoleh harga $t_{\text {hitung }}>t_{\text {tabel }}(16,19>1,992)$. Karena $t_{\text {hitung }}$ lebih besar dari $\mathrm{t}_{\text {tabel }}$ maka hal ini berarti $\mathrm{H}_{0}$ ditolak dan $\mathrm{H}_{1}$ diterima. Maka dapat disimpulkan bahwa terdapat pengaruh model pembelajaran CTL terhadap hasil belajar siswa pada materi Sistem Bahan Bakar Bensin Konvensional di kelas XI TBSM SMK Negeri 1 Palangka Raya tahun ajaran 2017/2018.

\section{UCAPAN TERIMA KASIH}

Ucapan terima kasih kepada: (1) Wiyogo, ST, MT selaku Dosen Pembimbing I, dan (2) Jhonni Rentas Duling, ST, MT selaku Dosen Pembimbing II.

\section{DAFTAR RUJUKAN}

Rusman. (2016). Model-model Pembelajaran Mengembangkan Profesionalisme Guru. Jakarta: PT. Rajagrafindo Persada.

Suhana, Cucu. (2014). Konsep Strategi Pembelajaran. Bandung: PT. Refika Aditama.

Undang-Undang Republik Indonesia No. 20 Tahun 2003, tentang Sistem Pendidikan Nasional. 